\title{
Padrões de fonte alimentar dos Flebotomíneos (Diptera: Psychodidae) vetores das Leishmanioses: uma revisão bibliográfica
}

\author{
Food source patterns of sandflies (Diptera: Psychodidae) vectors of leishmaniasis: a \\ literature review
}

Patrones de la fuente de alimento de los flebótomos (Diptera: Psychodidae) vectores de la leishmaniasis: revisión de la literatura

Raimundo Leoberto Torres de Sousa ${ }^{1 *}$, Sílvia Alcântara Vasconcelos ${ }^{2}$, Jacenir Reis dos SantosMallet $^{1,2,5}$, Elaine Ferreira do Nascimento ${ }^{2}$, Clarissa Romero Teixeira ${ }^{3}$, Cleanto Luiz Maia Silva ${ }^{4}$, Simone Mousinho Freire ${ }^{4}$, Anangela Ravena da Silva Leal ${ }^{1}$, Kitawann Tayrone de Sousa Nunes Cardoso $^{1,2}$, Maurício Luiz Vilela ${ }^{1,2}$, Regis Bernardo Brandim Gomes ${ }^{3}$.

\section{RESUMO}

Objetivo: Realizar levantamento da literatura de artigos sobre hábito e comportamento alimentar de flebotomíneos no Brasil. Métodos: Foram escolhidos nas bases de dados National Library of Medicine (NIHPub Med) e a biblioteca Scientific Electronic Library Online (SciELO), por meio das palavras chave "feeding preference"; "sandflies", "blood food sources" e "feeding behavior". Das quais, dos 290 trabalhos pesquisados, 20 foram escolhidos após análise dos critérios de inclusão. Resultados: O maior número de artigos publicados foi o ano 2005, onde foi possível observar diversos tipos de testes, tanto genéticos quanto imunoenzimáticos. as fontes de alimentação mais encontradas foram: aves, gambás, roedores, humanos, cavalos, cães, bovinos e gatos Considerações Finais: Foi possível observar que existem vários métodos de avaliação para identificar a fonte alimentar de flebotomíneos. Além disso, a análise dos artigos demonstrou que existe uma propensão dos insetos em se alimentar em animais próximos ao homem. Assim, espera-se que políticas sejam desenvolvidas para realizar um controle das formas aladas mais rigoroso. Este trabalho também ajudará pesquisadores a delimitar uma dinâmica de coleta mais especializada. Resolvendo todas as limitações que vierem a se manifestar neste tipo de pesquisa.

Palavras-chave: Psychodidae, Vetores, Flebótomos, Hábito alimentar.

\begin{abstract}
ABASTRACT
Objective: Conduct a survey of articles on the eating habits and behavior of sandflies in Brazil. Methods: Papers on the topic were chosen from the National Library of Medicine (NIH-PubMed) and Scientific Electronic Library Online (SciELO) databases, using the keywords "feeding preference"; "sandflies", "blood food sources" and "feeding behavior". From the 290 studies evaluated, 20 were chosen after analyzing the inclusion criteria. Results: The year that included the majority of published articles was 2005, when it was possible to observe different types of tests, both genetic and immunoenzymatic. The most common food sources identified were: birds, opossums, rodents, humans, horses, dogs, cattle and cats Final Considerations: It was possible to observe that there are several methods to identify the blood source for sandflies. In addition, there is evidence that there is a preference for insects to feed on animals the live close to humans. Thus, it is expected that public health policies should be developed to carry out a more rigorous control of adult sandflies. This work will also help researchers to define a more specialized collection dynamic, resolving any limitations that may arise in this type of research.
\end{abstract}

Key words: Psychodidae, Vectors, Sandflies, Feeding habit.

\footnotetext{
${ }^{1}$ Fundação Oswaldo Cruz (FIOCRUZ), Rio de Janeiro - RJ. *E-mail: leoberto_torres@outlook.com

${ }^{2}$ Fundação Oswaldo Cruz (FIOCRUZ), Teresina - PI.

${ }^{3}$ Fundação Oswaldo Cruz (FIOCRUZ), Fortaleza - CE.

4 Universidade Estadual do Piauí (UESPI), Teresina - PI.

${ }^{5}$ Universidade Iguaçu (UNIG), Rio de Janeiro - RJ.
} 


\section{RESUMEN}

Objetivo: Realizar un levantamiento de artículos sobre hábito y comportamiento alimentar de los flebótomos en Brasil. Métodos: Fueron elegidos en las bases de datos National Library of Medicine Biblioteca (NIH-Pub Med) y Scientific Electronic Library Online (SciELO), utilizando las palabras clave "feeding preference"; "sandflies", "blood food sources" e "feeding behavior". De las cuales, de los 290 trabajos investigados, 20 fueron elegidos tras análisis de los criterios de inclusión. Resultados: El año de mayor publicación de artículos fue 2005, en que fue posible observar diferentes tipos de pruebas, tanto genéticas como inmunoenzimáticas. Las fuentes de alimentación más comunes fueron: aves, zarigüeyas, roedores, humanos, caballos, perros, bovinos y gatos Consideraciones finales: Fue posible observar que existen varios métodos de evaluación para identificar la fuente alimentar de los flebótomos. Además, el análisis de los artículos demostró que existe una propensión de los insectos a alimentarse de animales cercanos al hombre. Así, se espera que se desarrollen políticas para realizar un control más riguroso de las formas aladas. Este trabajo también ayudará investigadores a delimitar una dinámica de recolección más especializada, resolviendo todas las limitaciones que puedan surgir en este tipo de investigación.

Palabras clave: Psychodidae, Vectores, Moscas de arena, Hábito de alimentación.

\section{INTRODUÇÃO}

Os flebotomíneos são insetos incriminados como transmissores de diferentes patógenos que causam diversas doenças, desde arboviroses em geral até bartonelose (doença bacteriana causada por bactérias do gênero Bartonella sp.) típica da região dos andes. (RANGEL EFR e LAINSON R, 2003). Entretanto, estes insetos possuem maior participação na transmissão de protozoários do gênero Leishmania sp causadores das leishmanioses no Brasil e no Mundo (WORLD HEALTH ORGANIZATION (WHO), 2018).

Os flebotomíneos (Díptera, Psychodidae) são divididos em sete gêneros: Phlebotomus, Rondani, 1840; Sergentomyia, França, 1924, Chinius, Leng, 1987, Brumptomyia, França e Parrot, 1921; Lutzomyia, França, 1924; Warileya, Hertig, 1948 e Edentomyia, Galati, 2003 (GALATI EAB, 2019). Taxonomicamente, são conhecidas mais de mil espécies de flebotomíneos ao redor globo, nas Américas, já foram identificadas 546 espécies nas Américas (GALATI EAB, 2019).

No Brasil, foram identificadas cerca de 230 espécies, das quais Nyssomyia whitmani, Nyssomyia intermedia e Migonemyia migonei, são incriminadas como vetores de espécies de Leishmania que causam a forma cutânea ou tegumentar e Lutzomyia longipalpis e Lutzomyia cruzi importantes vetores da espécie de Leishmania que causa a forma visceral (RANGEL EFR e LAINSON R, 2003; MISSAWA NA, et al., 2011).

Estes insetos são pequenos e possuem muitas cerdas espalhadas pelo corpo. Sua reprodução é do tipo holometábolo possuindo todas as formas evolutivas durante seu desenvolvimento, desde ovo e larva (com 4 estádios) até pupa e os adultos alados, quando apresentam dimorfismo sexual. As formas imaturas se desenvolvem em matéria orgânica em decomposição. $O$ aparelho bucal dos flebotomíneos apresenta aspecto picador sugador e é utilizada na aquisição de carboidratos como: frutas maduras seiva vegetal, néctar e excreções de afídeos (pulgões) (CAMERON MM, et al., 1995).

$\mathrm{Na}$ fase reprodutiva, as fêmeas se tornam hematófagas obrigatórias realizando alimentação sanguínea para estimular o desenvolvimento dos ovos, apesar de haver, em alguns casos, processos de autogenia (desenvolvimento de ovos sem necessidade de alimentação sanguínea) que, em geral, pode ocorrer na primeira postura de determinadas espécies (KAMHAWI S, 2000; READY PD, 1979; RANGEL EFR e LAINSON R, 2003; WORLD HEALTH ORGANIZATION, 2010). Assim, a preferência alimentar dos flebótomos possui uma tendencia bastante eclética, o que justifica sua presença em locais onde vivem galináceos, suínos, caprinos e equinos (BAUM M, et al., 2013).

Devido a diversidade genética das Leishmanias, é possível notar uma alta competência em infectar uma quantidade expressiva de hospedeiros. Esses hospedeiros podem ser classificados, de acordo com propriedades epidemiológicas em: Hospedeiros Primários (onde o parasita se desenvolve na ausência de outros reservatórios); Hospedeiros Secundários, (onde o hospedeiro é capaz de transmitir a leishmania para 
outros animais, mantendo o parasito latente em seu organismo sem desenvolve-lo), e Hospedeiro Acidental (que, em geral não transmite o parasito) (QUARESMA PF, et al., 2012).

Para Afonso MMS, et al. (2012), os vertebrados parasitados com a Leishmania, precisam estar inseridos em um sistema ecológico favorável ao desenvolvimento do parasita, de forma sólida e equilibrada em uma mesma escala espaço-temporal. Dessa forma, as características utilizadas para determinar uma espécie como reservatório são complexos dificultando a diferenciação entre hospedeiro primário e secundário. Com base nestas exposições, a infecção por Leishmanias sp. em animais silvestres, como: marsupiais, edentados, roedores, dentre outros e animais domésticos como equinos, canídeos domésticos e felinos, necessitam de uma série de estudos científicos que confirmem o papel destes como hospedeiros importantes para a saúde pública. (MINISTÉRIO DA SAÚDE, 2017).

No mundo é possível observar uma grande variedade de animais domésticos e silvestres participando da transmissão do parasito causador da Leishmaniose Visceral em diferentes focos da doença. Neste conjunto, o cão doméstico (Canis familiaris Linnaeus, 1758) possui uma importância epidemiológica expressiva na transmissão da Leishmaniose Visceral. Diversos critérios ambientais e clínicos como a presença de formas infectivas aos vetores no cão, a proximidade desses cães aos humanos como pets e a presença da doença na forma humana e canina em áreas endêmicas, indicam que o cão possui a capacidade de sustentar o ciclo da doença no peridomicílio confirmando seu papel como principal reservatório da LV no Brasil (AFONSO MM, et al., 2012).

Segundo Quaresma PF, et al. (2012), o estudo dos insetos vetores, especialmente no que diz respeito a fonte alimentar, tem grande importância ecoepidemiológica, uma vez que essas observações possibilitam a compreensão do hábito alimentar sanguíneo em hospedeiros na natureza apontando a função protetora que alguns animais são capazes de exercer em relação ao homem nas áreas de transmissão da doença.

Os flebotomíneos, ao realizarem alimentação sanguínea, levam em consideração uma série de variáveis como: temperatura, umidade relativa, iluminação e odores corporais (AFONSO MMS, et al., 2005), Pesquisas com fêmeas de Psychodopygus sanguinarius Mangabeira, 1942, Lutomyia gomezi Nitzulescu, 1931 e Lutomyia longipalpis Lutz \& Neiva, 1912 demonstraram que o tempo de alimentação em animais de sangue quente varia de 1 a 5 minutos porém, fêmeas de Lutzomyia stewarti Mangabeira \& Galindo, 1944 e Lutzmyia californica Fairchild \& Hertig, 1957 mostram que em animais de sangue-frio o tempo de alimentação pode chegar a 10 minutos (CHANIOTIS BM, 1967).

Ainda sobre esta questão, o comportamento alimentar, algumas espécies demonstram que não existe uma preferência bem definida, outras já possuem alimentação restrita a uma única espécie de vertebrado (CHANIOTIS BM, 1967). Para espécies como Lu. longipalpis, Ny. intermedia, Mg. migonei e Pintomyia fischeri, Pinto, 1926, a disposição por determinada fonte alimentar é inexistente, fazendo de animais como cães, gatos, aves, humanos, e outros animais alvos de alimentação sanguínea (RANGEL EFR e LAINSON $R, 2003)$.

Para avaliar os padrões de alimentação de um flebotomíneo, usa-se, como ferramenta principal, a análise da fonte alimentar destes insetos, tanto para identificar possíveis reservatórios de Leishmanias sp. quando para analise a positividade destes insetos quanto a presença do parasito e para o estudo da fonte alimentar emprega-se ferramentas como: ensaios de antígeno-anticorpo com a precipitina e o teste de ensaio Enzymelinked Lmmunosorbent Assay (ELISA) que se baseiam em reações antígeno-anticorpo, detectáveis por meio de reações imuno-enzimáticas. Entretanto, a exigências de sangue fresco, a baixa sensibilidade e a possibilidade de reação cruzada tornaram essas técnicas ultrapassadas (MARASSÁ AM, et al., 2004; SOUZA RCM e SOARES AC, 2011).

O teste mais adequado para o estudo do conteúdo estomacal das fêmeas é a Polymerase Chain Reaction (PCR), com esta técnica é possível amplificar uma única cópia de um segmento de DNA em várias, gerando milhões de cópias de uma determinada sequência. No caso do estudo do hábito alimentar, o marcador mitocondrial é o mais utilizado em sistemática molecular para determinar a identidade do reservatório utilizando o gene citocromo b (cyt b) (PEÑA VH, et al., 2012). 
Atualmente perspectivas moleculares, como a reação em cadeia da polimerase (PCR), vêm sendo usadas de forma mais expressiva em relação a outros métodos de análise. Estas estratégias de amplificação de genes mitocondriais, vêm sendo agregadas com alto índices de detecção. Entretanto, devido à resultados de especificidade inadequada na amplificação gênica, é necessário a utilização síncrona de técnicas auxiliares, como sequenciamento de DNA, que auxilia na aplicação e na confiabilidade do procedimento. Desta forma, o uso da PCR para identificação de preferência alimentar desenhados a partir do genoma mitocondrial de possíveis hospedeiros é uma escolha que irá colaborar com o aperfeiçoamento do tempo de análise e do custo desta técnica (PEÑA VH, et al., 2012).

Estes métodos ajudam a compreender como funciona o hábito alimentar dos vetores na natureza e como esse hábito influencia o comportamento reprodutivo, favorecendo o parasita na transmissão entre os reservatórios, este tipo de estudo pode auxiliar na criação de estratégias de controle das Leishmanioses (OLIVEIRA-PEREIRA YN, et al., 2008).

Diante disso, a revisão tem por objetivo responder às seguintes questões: Qual a preferência alimentar sanguínea dos flebotomíneos e se essa preferência afeta a disseminação da leishmaniose, além disso, visa fornecer e discutir sobre os hábitos alimentares das fêmeas de flebotomíneos descritos na literatura.

\section{MÉTODOS}

Esta revisão foi realizada para proporcionar a união de resultados a partir de outras pesquisas que tratam a respeito deste tema, através de levantamento bibliográfico, contribuindo para um maior aprofundamento do assunto (SOUZA MT, 2010).

Foram escolhidos trabalhos sobre o tema proposto, tendo como base de dados a National Library of Medicine (NIH-Pub Med) e a biblioteca Scientific Electronic Library Online (SciELO). A pesquisa ocorreu por meio da seleção dos Descritores em Ciências da Saúde (DeCS): "feeding preference"; "sandflies", "blood food sources" e "feeding behavior". Além destes, foi usado também o operador booleano "and", que permitiu acessar os artigos que possuem intersecção entre as diferentes palavras chaves.

Como critérios de seleção foram considerados: Idioma (Inglês e Português); Período em que foram publicados (Entre 2003 a 2021). Uma vez que, pela baixa quantidade de artigos recentes, o recorte temporal foi expandido para ter maior abrangência na revisão integrativa; Base de dados online (NIH-Pub Med) e biblioteca cientifica online SciELO; Tipo de estudo (artigos); e local de pesquisa (Brasil). Os critérios de exclusão foram: artigos que se repetiram nas bases de dados e que não tinham o Brasil como região específica de análise, revisões, dissertações, teses, monografias e resumos expandidos (Figura 1).

Foram encontrados um total de 290 trabalhos, das quais foram excluídos 270 pelos critérios de exclusão já mencionados. Resultando, ao final da busca, em 20 estudos científicos que foram categorizados e avaliados para a interpretação dos dados. Foi realizado, também, através do Software PAST versão 4.03, um teste de similaridade de Jaccard. Este teste é utilizado, em ecologia, para indicar a semelhança entre duas comunidades, comparando o número de espécies entre as áreas estudadas. Entretanto, foi realizada uma adaptação nos cálculos trocando as comunidades pelos reservatórios a fim de verificar a similaridade entre as escolhas de vertebrados para repasto sanguíneo feito pelas espécies de flebotomíneos a fim de analisar as possíveis preferências e a proximidade do reservatório escolhido com o ser humano. 
Figura 1 - Critérios de inclusão e exclusão dos trabalhos analisados para realização da revisão integrativa.

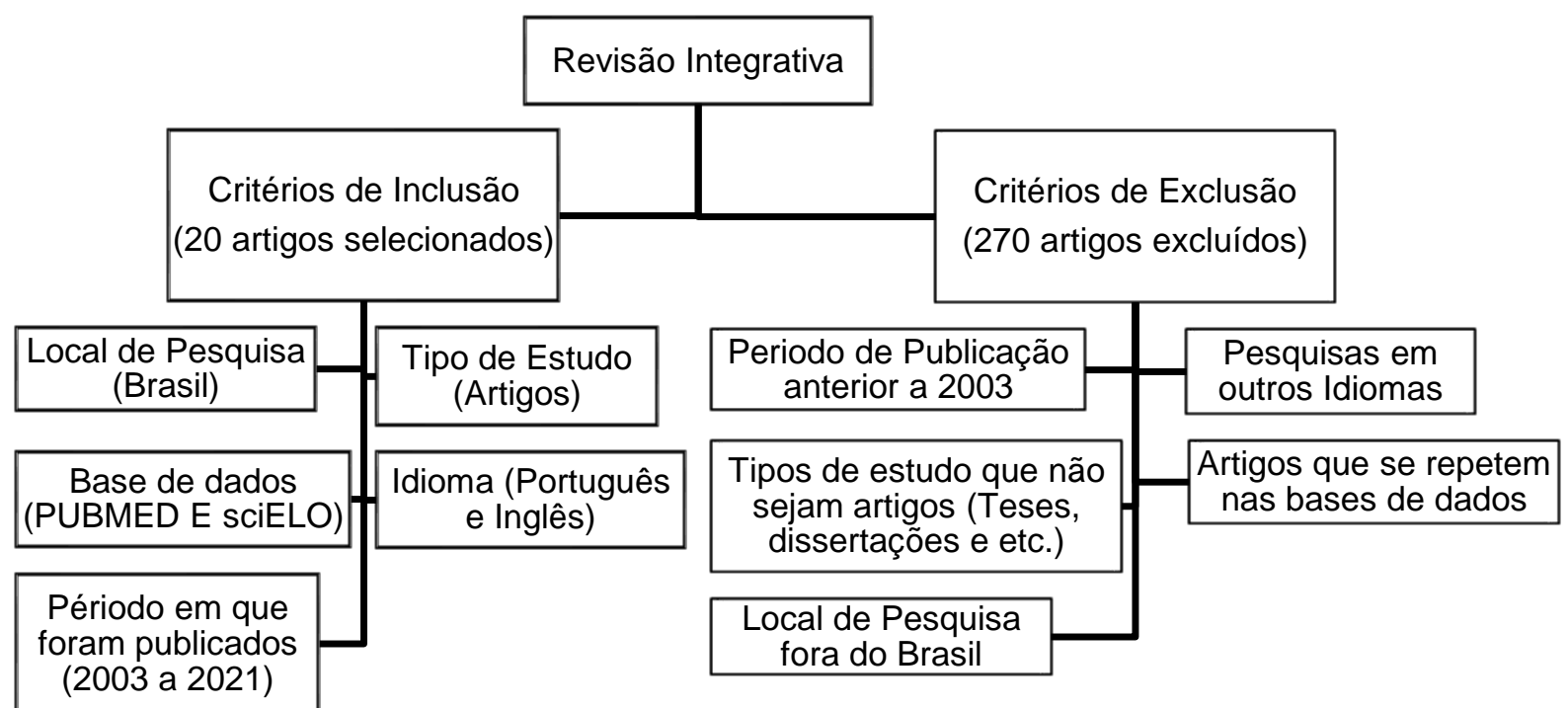

Fonte: Sousa RLT, et al., 2021.

\section{RESULTADOS E DISCUSSÃO}

De acordo com os critérios de escolha, foram selecionados 20 artigos que seguiam os critérios de escolha, conforme apresentado na Tabela 1. 
Quadro 1 - Artigos selecionados segundo os critérios de inclusão

\begin{tabular}{|c|c|c|c|c|c|c|}
\hline \multirow{2}{*}{$\mathbf{N}^{\circ}$} & \multirow{2}{*}{ Autores } & \multicolumn{5}{|c|}{ Principais Achados } \\
\hline & & Ec & UF & Testes & Sp. & Sangue Encontrado \\
\hline 1 & DIAS FD, et al., 2003. & Peri & MA & Precipitina & Lu. longipalpis & $\begin{array}{l}\text { Ave; roedor; humano; cão; mucura } \\
\text { (gambá); equino; gato; guaxinim }\end{array}$ \\
\hline 2 & NERY LCDR, et al., 2004. & Peri & AM & Precipitina & $\begin{array}{l}\text { Ny umbratilis } \\
\text { Lu. spathotrichia } \\
\text { Ny. anduzei } \\
\text { Ps. shannoni }\end{array}$ & $\begin{array}{c}\text { Roedor; canídeos; edentado; humanos; } \\
\text { aves }\end{array}$ \\
\hline 3 & AFONSO MMS, 2005. & Intra Peri & RJ & Precipitina & Ny. intermedia & Ave; cão; equino; roedores \\
\hline 4 & SOUZA NA, 2005a. & Floresta Peri & RJ & N. A & $\begin{array}{l}\text { Ny. intermedia } \\
\text { Ny. whitmani }\end{array}$ & Humanos \\
\hline 5 & SOUZA NA, 2005b. & Floresta Peri & RJ & N. A & $\begin{array}{l}\text { Ny. intermedia } \\
\text { Ny. whitmani }\end{array}$ & Humanos \\
\hline 6 & MARASSÁ AM, et al., 2006. & Peri & MS & ELISA & $\begin{array}{l}\text { Lu. longipalpis } \\
\text { Lu. almerioi }\end{array}$ & Ave \\
\hline 7 & SVERSUTTI D, et al., 2007. & Peri & PR & Precipitina/ELISA & $\begin{array}{c}\text { Ny. neivai } \\
\text { Ny. whitmani } \\
\text { Pi. fischeri } \\
\text { Pi. monticola } \\
\text { Ev. correalimai } \\
\text { Ev. cortelezzii } \\
\text { Ex. firmatoi } \\
\text { Mi. ferreirana } \\
\text { Mi. migonei } \\
\text { Br. brumpti } \\
\text { Pi. pessoai } \\
\text { Ps. lanei } \\
\text { Ps. shanonni }\end{array}$ & Cão; suíno; galinhas; coelhos \\
\hline 8 & MISSAWA NA, et al., 2008. & Intra Peri & MT & Precipitina & Lu. longipalpis & $\begin{array}{l}\text { Ave; boi; cão; cavalo } \\
\text { Gambá; humano; roedor }\end{array}$ \\
\hline 9 & $\begin{array}{l}\text { OLIVEIRA-PEREIRA YN, et } \\
\text { al., } 2008 .\end{array}$ & Peri & MA & Precipitina & $\begin{array}{l}\text { Pr. choti } \\
\text { Pr. triacantha } \\
\text { Ny. whitmani }\end{array}$ & $\begin{array}{l}\text { Ave; boi; cão; equino; humano; mucura; } \\
\text { roedor }\end{array}$ \\
\hline 10 & QUARESMA PF, et al., 2012. & Peri & $M G$ & PCR & Ps. Iloydi & Roedor; marsupial; humano; ave \\
\hline
\end{tabular}




\begin{tabular}{|c|c|c|c|c|c|c|}
\hline \multirow{2}{*}{$\mathbf{N}^{\circ}$} & \multirow{2}{*}{ Autores } & \multicolumn{5}{|c|}{ Principais Achados } \\
\hline & & Ec & UF & Testes & Sp. & Sangue Encontrado \\
\hline 11 & AFONSO MMS, et al., 2012. & Peri & $\begin{array}{l}\mathrm{BA} \\
\mathrm{CE} \\
\mathrm{PI}\end{array}$ & ELISA & Lu. longipalpis & $\begin{array}{l}\text { Pássaro; cão; bode; gambá; equino; } \\
\text { felino; humano; ovelha; roedor }\end{array}$ \\
\hline 12 & MARASSÁ AM, et al., 2013. & Peri & $\mathrm{SP}$ & ELISA & $\begin{array}{l}\text { Ny. Intermedia } \\
\text { Ny. neivai }\end{array}$ & Humano; frango; porco; cão \\
\hline 13 & BAUM M, et al., 2013. & $\begin{array}{l}\text { Intra Peri } \\
\text { Floresta }\end{array}$ & PR & Precipitina & Ny. intermedia & $\begin{array}{l}\text { Pássaros; gambás; roedores; humanos; } \\
\text { cães; cavalos; gado; gatos }\end{array}$ \\
\hline 14 & SOARES VY, et al., 2014. & Peri & $\mathrm{PI}$ & PCR & Lu. longipalpis & $\begin{array}{l}\text { Humano; roedor; gambá; cão; gato; } \\
\text { porco; bovino; galinha; equino; raposa }\end{array}$ \\
\hline 15 & BRITO VND, et al., 2014 & Peri & MT & ELISA/PCR & $\begin{array}{c}\text { Lu. cruzi } \\
\text { Ny. whitmani }\end{array}$ & Ave; cão; gambá \\
\hline 16 & SILVA ASGE, et al., 2014. & Peri & $\mathrm{RN}$ & PCR & $\begin{array}{c}\text { Lu. longipalpis } \\
\text { Ev. evandroi } \\
\text { Ev. lenti } \\
\text { Ny. whitmani }\end{array}$ & $\begin{array}{l}\text { Humano; roedor; cavalo; cão; gato; } \\
\text { frango; gambá; sagui }\end{array}$ \\
\hline 17 & TANURE A, et al., 2015. & Intra Peri & $M G$ & ELISA & $\begin{array}{l}\text { Ev. cortelezzii } \\
\text { Lu. longipalpis }\end{array}$ & Frango; cão; humano; roedor \\
\hline 18 & BAUM M, et al., 2015. & $\begin{array}{l}\text { Intra Peri } \\
\text { Floresta }\end{array}$ & PR & PCR & $\begin{array}{l}\text { Ny. intermedia } \\
\text { Ny. neivai }\end{array}$ & Javali; cão; equino \\
\hline 19 & SILVA ASGE, et al., 2017. & Peri & MA & PCR & $\begin{array}{c}\text { Lu. longipalpis } \\
\text { Ev. evandroi } \\
\text { Sc. sordellii } \\
\text { Ev. lenti } \\
\text { Ny. whitmani } \\
\text { Mi. trinidadensis } \\
\text { Ev. termitophila }\end{array}$ & $\begin{array}{c}\text { Cão; humano; roedor; galinha; gado; } \\
\text { porco; equino; gambá }\end{array}$ \\
\hline 20 & COSTA JCR, et al., 2021. & Caverna & $M G$ & PCR & $\begin{array}{l}\text { Sc. microps } \\
\text { Sc. sordellii } \\
\text { Mt. oliveirai }\end{array}$ & Anfíbios. \\
\hline
\end{tabular}

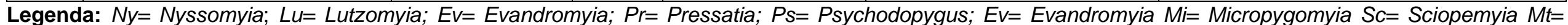

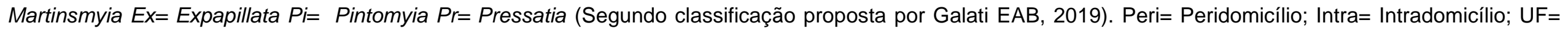
Unidades Federativas; N. A= Não Analisado. Fonte: Sousa RLT, et al., 2021. 
Os mamíferos mais encontrados foram cão, humano e roedor com 15, 13 e 12 notificações respectivamente, demonstrando uma forte preferência dos flebotomíneos por esses vertebrados em relação aos demais analisados (Gráfico 1A). O período de publicação variou entre os anos de 2003 e 2021, com predominância de $16,6 \%$ dos estudos divulgados no ano de 2005, seguido do ano de 2012 e 2015 com 11,1\% respectivamente (Gráfico 1B). As espécies de flebotomíneos mais encontradas foram Lu. longipalpis, $\mathrm{Ny}$ whitmani, Ny. Intermedia, sendo o primeiro, vetor comprovado da LV e os dois últimos, vetores comprovados da LTA (Gráfico 1C).

Gráfico 1 - Análise da distribuição de espécies de vetores de Leishmania spp., seus respectivos repastos sanguíneos e a distribuição da quantidade de trabalhos por ano de publicação.
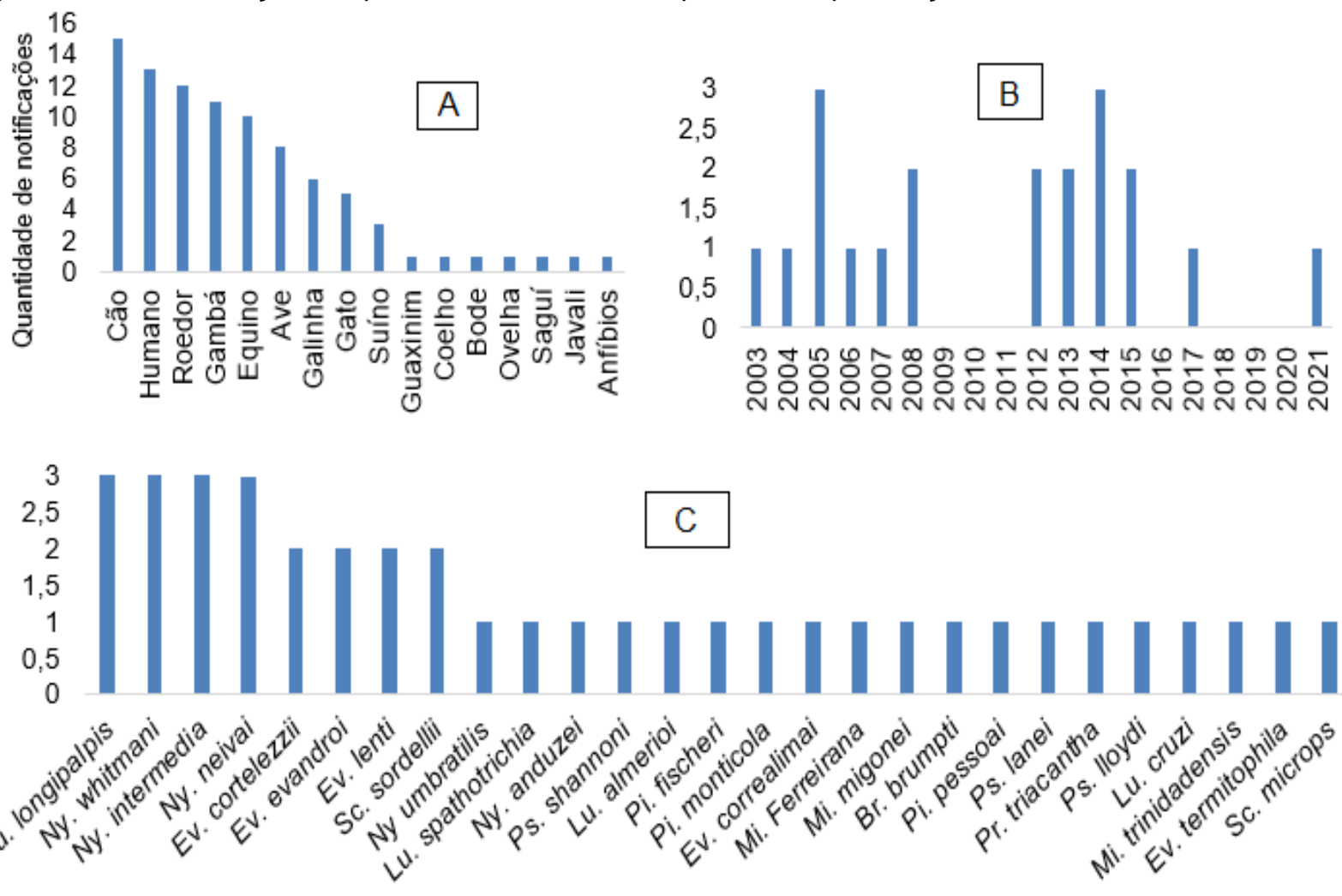

- Quantidade de espécies.

Legenda: $\mathbf{A}=$ Quantidade de notificações de repasto sanguíneo $\mathbf{B}=$ Quantidade de artigos publicados entre 2003 e 2021; C = Principais espécies de flebotomíneos encontrados.

Fonte: Sousa RLT, et al., 2021.

Analisando o grau de similaridade entre os reservatórios escolhidos pelas fêmeas das diversas espécies de flebotomíneos encontradas, foi possível observar, usando o índice de Jaccard adaptado, que os roedores compartilhavam $93,8 \%$ de similaridade com o ser humano. Além disso, humano, roedor, gambá e equino, compartilham $81,0 \%$ de similaridade com o cão, demostrando que por mais que os flebótomos tenham uma tendência por escolhas aleatórias de reservatórios, há uma preferência em escolher vertebrados com relativa proximidade com o ser humano, favorecendo o trânsito da Leishmania sp. entre as espécies (Figura 2). 
Figura 2 - Dendrograma de coeficiente de similaridade de Jaccard adaptado entre os diversos reservatórios escolhidos pelos flebotomíneos para o repasto sanguíneo.

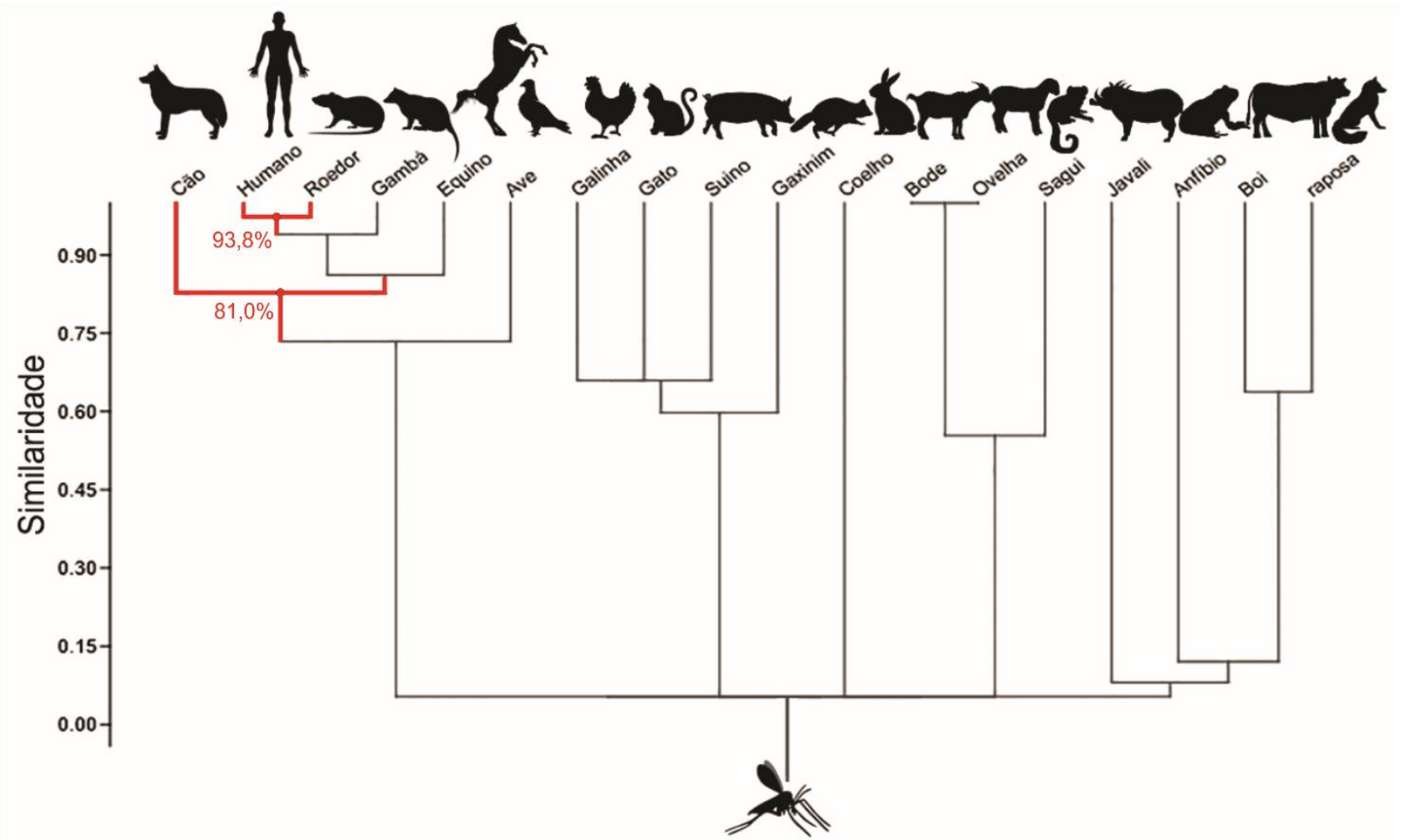

Fonte: Sousa RLT, et al., 2021.

Das áreas analisadas o Sudeste apresenta $31,2 \%$, de publicações compreendendo Rio de Janeiro; Minas Gerais e São Paulo, o Nordeste apresentou 31,2\% sendo os estados da Bahia, Ceará, Piauí, Rio Grande do Norte e Maranhão e o Centro-Oeste apresentou 18,7\%, onde os estados com publicações foram Mato Grosso e Mato Grosso do Sul. Os dados sobre a epidemiologia destas regiões demonstram que existe um aumento de casos humanos de LV e LTA e, talvez, este fenômeno explique a grande quantidade estudos nestas regiões.

Dos trabalhos analisados, 50,0\% realizaram capturas em áreas de peridomicílio, 22,2\% foram realizados em área intradomicíliar e peridomicíliar de forma simultânea e 22,0\% foram coletados em áreas de florestas semideciduais de Mata Atlântica de forma simultânea com os demais ecótopos. Isso se deve ao fato das fêmeas de flebótomos apresentarem características antropofílicas e ter tropismo pelos ambientes externos das residências (BAUM M, et al., 2013).

Quanto aos testes analisados, os mais utilizados foram os testes de precipitina com $33,3 \%$, ELISA com $38,8 \%$, e PCR com $27,7 \%$. Assim, pode-se perceber uma tendência pela escolha do teste de ELISA, devido a sensibilidade e especificidade marcante em relação à pouca quantidade de sangue disponível. Além disso, o teste de ELISA é mais acessível e barato em comparação com testes moleculares, o que pode garantir melhores resultados, com exceção da PCR que possui um desempenho melhor em relação a testes mais baratos (MARASSÁ AM, et al., 2004)

Com relação aos vetores, a pesquisa mostrou que as espécies mais coletadas foram Nyssomyia whitmani e Nyssomyia intermedia e nas demais áreas de estudo a espécie mais encontrada foi Lutzomyia longipalpis. Este resultado demonstra que Lu. longipalpis, Ny intermedia e Ny whitmani são as espécies mais encontradas em regiões que compreendem desde o norte do Mato Grosso até o sul do Paraná, os estudos demonstram que $\mathrm{Ny}$. intermedia e Lu. longipalpis possuem preferência alimentar eclética, porém, com tendencia para realizar alimentação sanguíneo em animais como: aves; humanos e roedores (MISSAWA NA, 2008; BAUM M, et al., 2015; AFONSO MMS, 2005; MARASSÁ AM, et al., 2013), 
Segundo os dados do Manual de Vigilância da Leishmaniose Visceral, o cão (Canis familiaris) é a principal fonte de infecção de Leishmania no ambiente doméstico, além disso, casos de leishmaniose canina tem precedido a ocorrência de casos humanos, sendo a infecção nos cães mais frequente do que em humanos. No ambiente silvestre, os mamíferos reservatórios mais comuns são as raposas e os marsupiais do gênero Didelphis sp., nesta revisão foi possível notar a presença de ambos, porém, de acordo com o grau de similaridade, parece haver uma tendência por realizar repastos em gambás do que em raposas (MINISTÉRIO DA SAÚDE, 2017).

Embora o cão seja descrito como reservatório da L. infantum, L. donovani, L. tropica, L. brasiliensis, $L$. panamensis, L. mexicana e L. peruviana com um período de incubação de 1 mês a 4 anos, a sintomatologia no cão apresenta caráter multissistêmico, ou seja, afeta todos os sistemas do corpo, além disso, o parasito pode ser encontrado em quaisquer tecidos e/ou órgãos provocando alterações imunológicas (AFONSO MM, 2005). Assim, os principais sintomas da LV canina são: alopecia, dermatites, descamações, dentre outros sinais cutâneos; conjuntivite, ceratoconjuntivite, e outros sinais oculares; caquexia; linfoadenopatia; anemia; febre e hepatoesplenomegalia. De acordo com os sintomas apresentados os cães podem ser categorizados em assintomático, oligossintomáticos e sintomáticos (AFONSO MMS, 2005).

Pesquisas demonstram que em áreas de foco para LV canina a maioria dos cães é assintomático e fonte de infecção para os insetos vetores. O fato destes animais estarem assintomáticos, ou com sintomas sugestivos leves, dificulta o diagnóstico da doença enfatizando a relevância do uso de testes sorológicos confiáveis a fim de auxiliar na detecção e eliminação dos animais soropositivos (MINISTÉRIO DA SAÚDE 2017). Diversos estudos demonstraram que o agente etiológico da LTA já foi encontrado em espécies de animais silvestres, sinantrópicos e domésticos desde canídeos e felídeos até bovinos e equinos, entretanto, com relação aos equinos, seu papel na manutenção do parasito ainda não foi comprovado (BRASIL, 2017).

Em relação à alimentação de flebotomíneos em aves, as galinhas são refratárias à infecção por Leishmania sp. tanto pela temperatura corporal mais elevada que pode chegar a $41^{\circ} \mathrm{C}$, quanto pela diferença biológica próprias das galinhas, como os glóbulos vermelhos nucleados (SCHLEIN Y, et al., 1983). O repasto sanguíneo em galinhas pode destruir os parasitas estabelecidos, tornando os insetos temporariamente ineficazes na transmissão do parasita a outros reservatórios (ALEXANDER, et al. 2002). Entretanto, a proximidade de galinheiros às residências é comumente considerada um fator de risco, pois, as fêmeas de flebotomíneos sendo ecléticas e atraídas por essas aves, podem vir a realizar repasto no ser humano mais próximo (CALDAS AJ, et al., 2002).

Outro reservatório silvestre que, aparentemente, não possui importância médica comprovada, mas que precisa estar em constante observação são os anfíbios (ordem Anura) que podem abrigar diversas espécies de tripanossomatídeos (COSTA JCR, et al., 2021). Determinadas espécies de Phlebotomine foram observadas realizando repasto sanguíneo em rãs, esses flebotomíneos, especificamente os gêneros Evandromyia, Lutzomyia, Psathyromyia e Sciopemyia foram identificados por técnicas de PCR com a presença de tripanossomatídeos. Espécies dos gêneros Sciopemyia e Evandromyia podem ser encontradas em diversos locais escuros e úmidos como tocas terrestres que abrigam rãs capazes de se infectar com tripanossomos indicando que esses flebotomíneos realizam repasto sanguíneo em animais de sangue frio (COSTA JCR, et al., 2021).

Para Costa JCR, et al. (2021), flebotomíneos têm sido constantemente encontrados habitando regiões de cavernas onde podem realizar repasto sanguíneo em animais como: pássaros, roedores, morcegos, e lagartos. Gêneros como Sciopemyia sp. foram registradas em cavernas em estados como Amazonas, Mato Grosso do Sul, Minas Gerais e Rondônia. Apesar desse estudo, os dados sobre o repasto sanguíneo do gênero Sciopemyia em ambientes cavernícolas são limitados. É possível observar artigos de espécimes de Sc. sordellii parasitados com Leishmania sp, entretanto o papel dessa espécie na transmissão ainda não foi devidamente comprovado.

Os resultados da análise de frequência horária mostram que o comportamento alimentar destes insetos atinge seu ápice no período noturno. Segundo Souza, et al. (2005a), Ny. intermedia e Ny. whitmani apresentam alterações acentuadas em suas preferências para realizar alimentação sanguíneo em humanos, 
com pico de atividade entre 04:00h e 06:00h horas da manhã. Além disso foi possível constatar que $N y$. whitmani possui taxas de alimentação mais altas do que $\mathrm{Ny}$. intermedia.

Vários motivos afetam o comportamento alimentar dos flebotomíneos, entre eles: umidade relativa pluviometria e temperatura além do ciclo lunar, onde é possível observar que há uma correlação positiva entre a intensidade da luz da lua, nas fases de lua nova e minguante, e o número de fêmeas de $\mathrm{Ny}$. intermedia e Ny. whitmani capturadas durante o repasto sanguíneo (SOUZA NA, et al., 2005b).

Evidências epidemiológicas mostram que, em geral, áreas endêmicas para leishmanioses estão geograficamente correlacionadas a áreas com determinada cobertura vegetal e, em alguns casos, com pouca densidade demográfica. Para Guimarães FN, et al. (1968), várias espécies de roedores, quando afugentados de áreas silvestres, migram para localidades com focos de leishmaniose em áreas rurais, posteriormente para áreas periurbanas e, por fim chegando a áreas urbanizadas, onde o cão, em relação à leishmaniose visceral, torna-se o reservatório doméstico do protozoário resultando em riscos para a população humana, decorrente das alterações ambientais, se constituindo em um problema de saúde pública.

\section{CONSIDERAÇÕES FINAIS}

Na presente revisão, foi possível observar a existência de vários métodos para identificar a fonte alimentar de flebotomíneos no Brasil. Além disso, a análise dos artigos demonstrou que embora eclética, existe uma propensão dos flebotomíneos em se alimentar em animais que estão próximos ao ser humano aumentando as chances de casos de leishmaniose. Assim, espera-se que políticas públicas sejam desenvolvidas com o objetivo de realizar um controle das formas aladas mais efetivo, resultando em progressos no controle da doença no país com base no conhecimento da preferência alimentar destes vetores. Esta revisão pretende contribuir com pesquisadores e especialistas da área, no sentido de delimitar uma dinâmica de coleta mais especializada, objetivando obter mais dados de como controlar a transmissão das leishmanioses. e resolver limitações que vão desde dificuldade na captura de fêmeas ingurgitadas até execução de análises moleculares

\section{REFERÊNCIAS}

1. AFONSO MMS, et al. Studies on the feeding habits of Lutzomyia (N.) intermedia (Diptera, Psychodidae), vector of Cutaneous Leishmaniasis in Brazil. Cadernos de Saúde Pública, 2005; 21(6): 1816-1820.

2. AFONSO MMS, et al. Studies on the Feeding Habits of Lutzomyia (Lutzomyia) longipalpis (Lutz \& Neiva, 1912) (Diptera: Psychodidae: Phlebotominae) Populations from Endemic Areas of American Visceral Leishmaniasis in Northeastern Brazil. Journal of Tropical Medicine, 2012; 2012: 1-5.

3. ALEXANDER B, et al. Role of the domestic chicken (Gallus gallus) in the epidemiology of urban visceral leishmaniasis in Brazil. Emerging Infectious Diseases journal. 2002; 8: 1480-1485.

4. BAUM M, et al. Eclectic feeding behavior of Lutzomyia (Nyssomyia) intermedia (Diptera, Psychodidae, Phlebotominae) in the transmission area of American Cutaneous Leishmaniasis, state of Paraná, Brazil. Revista da Sociedade Brasileira de Medicina Tropical, 2013; 46(5): 560-565.

5. BAUM M, et al. Molecular detection of the blood meal source of sand flies (Diptera: Psychodidae) in a transmission area of American Cutaneous Leishmaniasis, Paraná State, Brazil, Acta Tropica, 2015; 143: 8-12.

6. BRITO VND, et al. Phlebotomine fauna, natural infection rate and feeding habits of Lutzomyia cruzi in Jaciara, state of Mato Grosso, Brazil. Memórias do Instituto Oswaldo Cruz, 2014; 109(7): 899-904.

7. CHANIOTIS BN. The Biology of California Phlebotomus (Diptera: Psychodidae) Under Laboratory Conditions. Journal of Medical Entomology. 1967 ;4(2): 221- 33.

8. CALDAS AJ, et al. Risk factors associated with asymptomatic infection by Leishmania chagasi in north-east Brazil. Transactions of the Royal Society of Tropical Medicine and Hygiene, 2002; 96: 21-28

9. CAMERON MM, et al. Sugar meal sources for the phlebotomine sandfly Lutzomyia longipalpis in Ceará State, Brazil. Medical and Veterinary Entomology, 1995; 9(3): 263-272.

10. COSTA JCR, et al. First molecular evidence of frogs as a food source for sand flies (Diptera: Phlebotominae) in Brazilian caves. Parasitology Research, 2021; 120(5): 1571-82.

11. DIAS FDOP, et al. Fonte alimentar sangüínea e a peridomiciliação de Lutzomyia longipalpis (Lutz \& Neiva, 1912) (Psychodidae, Phlebotominae). Cadernos de Saúde Pública, 2003; 19(5): 1373-1380.

12. GALATI EAB. Morfologia e terminologia de Phlebotominae (Diptera: Psychodidae). Classificação e identificação de táxons das Américas. Faculdade de Saúde Pública da Universidade de São Paulo, 2019; 1. 
13. GALATI EAB. Morfologia e Taxonomia: Classificação de Phlebotominae. In: RANGEL EF, LAISON R. Flebotomíneos do Brasil. Rio de Janeiro: FIOCRUZ, 2003; 133-142p

14. GUIMARÃES FN. Leishmaniose Tegumentar - zoonose de roedores silvestres na Amazônia. Memórias do Instituto Oswaldo Cruz, 1968 66(2): 151-168.

15. HAOUAS N, et al. Development of a molecular tool for the identification of Leishmania reservoir hosts by blood meal analysis in the insect vectors. Transactions of the Royal Society of Tropical Medicine and Hygiene, 2007; 77(6): 10541059.

16. KAMHAWI S. The biological and immunomodulatory properties of sand fly saliva and its role in the establishment of Leishmania infections. Microbes and Infection, 2000; 2(14): 1765-1773.

17. MARASSÁ AM, et al. Identificação do sangue ingerido por Lutzomyia (Lutzomyia) longipalpis (Lutz \& Neiva, 1912) e Lutzomyia (Lutzomyia) almerioi (Galati \& Nunes, 1999) pela técnica imunoenzimática do ELISA de captura, no sistema avidina-biotina. Revista da Sociedade Brasileira de Medicina Tropical, 2006; 39(2): 183-186.

18. MARASSÁ AM, et al. Padronização da técnica imunoenzimática do ELISA de captura, no sistema avidina-biotina para a identificação de sangue ingerido por Lutzomyia (Lutzomyia) longipalpis (Lutz \& Neiva, 1912). Revista da Sociedade Brasileira de Medicina Tropical, 2004; 37(6): 441-446.

19. MARASSÁ AM, et al. Blood feeding patterns of Nyssomyia intermedia and Nyssomyia neivai (Diptera, Psychodidae) in a cutaneous leishmaniasis endemic area of the Ribeira Valley, State of São Paulo, Brazil. Revista da Sociedade Brasileira de Medicina Tropical, 2013; 46(5): 547-554.

20. MARCONDES, C. B. 2007. A proposal of generic and subgeneric abbreviations for Phlebotomine sandflies (Diptera: Psychodidae: Phlebotominae) of the world. Entomol. News 2007; 118: 351-356.

21. MINISTÉRIO DA SAÚDE. Manual de Vigilância e Controle da Leishmaniose Tegumentar. Brasil, 2017. Disponível em: $\quad$ http://vigilancia.saude.mg.gov.br/index.php/download/manual-de-vigilancia-da-leishmaniose-tegumentar/. Acesso em: 16 de junho de 2021.

22. MISSAWA NA, et al. Preferência alimentar de Lutzomyia longipalpis (Lutz \& Neiva, 1912) em área de transmissão de Leishmaniose Visceral em Mato Grosso. Revista da Sociedade Brasileira de Medicina Tropical, 2008; 41(4): $365-368$.

23. MISSAWA NA, et al. Evidência de transmissão de leishmaniose visceral por Lutzomyia cruzi no município de Jaciara, Estado de Mato Grosso, Brasil. Revista da Sociedade Brasileira de Medicina Tropical, 2011; 44(1): 76-78.

24. NERY LCDR, et al. Feeding preference of the sand flies Lutzomyia umbratilis and L. spathotrichia (diptera: Psychodidae, Phlebotominae) in an urban forest patch in the city of Manaus, Amazonas, Brazil. Memórias do Instituto Oswaldo Cruz, 2004; 99(6): 571-574.

25. OLIVEIRA-PEREIRA YN, et al. Preferência alimentar sanguínea de flebotomíneos da Amazônia do Maranhão, Brasil. Cadernos de saúde pública, 2008; 24(9): 2183-2186.

26. PEÑA VH, et al. High-resolution melting (HRM) of the cytochrome B gene: a powerful approach to identify blood-meal sources in Chagas disease Vectors. PLoS neglected tropical diseases, 2012; 6(2): 1530.

27. QUARESMA PF, et al. Natural Leishmania sp. reservoirs and phlebotomine sandfly food source identification in Ibitipoca State Park, Minas Gerais, Brazil. Memórias do Instituto Oswaldo Cruz, 2012; 107(4): 480-485.

28. RANGEL EF, LAINSON R. Flebotomíneos no Brasil. Rio de Janeiro: FIOCRUZ, 2003; 207-255p.

29. READY PD, Factors affecting egg production of laboratory-bred Lutzomyia longipalpis (Diptera: Psychodidae). Journal of medical entomology, 1979; 16(5): 413-423.

30. SCHLEIN Y, et al. Vector compatibility of Phlebotomus papatasti on differentially induced digestion. Acta Tropica, 1983; 40: 65-70.

31. SILVA ASGE, et al. Leishmania infection and blood food sources of phlebotomines in an area of Brazil endemic for visceral and Tegumentary Leishmaniasis. PLoS ONE, 2017; 12(8): 1-19.

32. SOARES VY. et al. Identification of blood meal sources of Lutzomyia longipalpis using polymerase chain reactionrestriction fragment length polymorphism analysis of the cytochrome B gene Memórias do Instituto Oswaldo Cruz, 2014; 109(3): 379-383.

33. SOUZA MT. Revisão integrativa: o que é e como fazer. Revista Einstein, 2010; 8(1): 102-106.

34. SOUZA NA, et al. Moonlight and blood-feeding behaviour of Lutzomyia intermedia and Lutzomyia whitmani (Diptera:Psychodidae:Phlebotominae), vectors of American Cutaneous Leishmaniasis in Brazil. Memórias do Instituto Oswaldo Cruz, 2005b; 100(1): 39-42.

35. SOUZA NA, et al. Nocturnal activity rhythms of Lutzomyia intermedia and Lutzomyia whitmani (Diptera: Psychodidae) in a transmission area of American Cutaneous Leishmaniasis in Rio de Janeiro State, Brazil. Journal of medical entomology, 2005a; 42(6): 986-992.

36. SOUZA RDC, et al. Feeding behavior of Triatoma vitticeps (Reduviidae: Triatominae) in the state of Minas Gerais, Brazil. Memórias do Instituto Oswaldo Cruz, 2011; 106(1): 16-22.

37. SVERSUTTI D, et al. Estudo Preliminar da preferência alimentar de Nyssomyia neivae (Pinto) e Nyssomyia whitmani (Antunes \& Coutinho) (Diptera: Psychodidae) em área rual do Paraná. Neotropical entomology, 2007; 36(6): 953-956.

38. TANURE, A. et al. Identification of Sandflies (Diptera: Psychodidae: Phlebotominae) Blood Meals in Endemic Leishmaniasis Area in Brazil. Revista do Instituto de Medicina Tropical, 2015; 54(4): 321-324.

39. WORLD HEALTH ORGANIZATION (WHO): Leishmaniasis. 2018. Disponível em: https://www.who.int/healthtopics/leishmaniasis\#tab=tab_1. Acesso em: 16 de junho de 2021. 